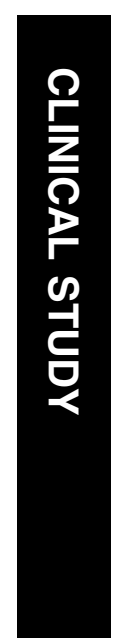

\section{The Cataract}

National Dataset

Electronic Multi-

centre Audit of

55567 operations:

anaesthetic

techniques and

complications

'Eye Department, St James' University Hospital, Leeds, UK

\section{${ }^{2}$ Gloucestershire Eye} Department, Gloucestershire Hospitals NHS Foundation Trust, Cheltenham General Hospital, Cheltenham, UK

${ }^{3}$ Bristol Eye Hospital, Bristol, UK

\section{${ }^{4}$ Ophthalmology} Department, Norfolk and Norwich University Hospital, Colney, Norwich, UK

${ }^{5}$ International Centre for Eye Health, London School of

Hygiene \& Tropical

Medicine, London, UK

\section{Correspondence:}

RL Johnston,

Gloucestershire Eye

Department,

Cheltenham General

Hospital,

Sandford Road,

Cheltenham GL537AN,

UK

Tel: + 441242 272529;

Fax: +44 1242272585

E-mail: rob.johnston@

glos.nhs.uk

Received: 24 July 2007 Accepted in revised form: 2 October 2007

Published online: 14 March 2008

\begin{abstract}
Purpose The primary aim of this study was to detail anaesthetic techniques and complications for cataract surgery in the UK. Methods The Cataract National Dataset was extracted from 12 National Health Service Trusts that used the same electronic patient record system between November 2001 and July 2006 on a total of 55567 cataract operations.
\end{abstract}

Results Anaesthesia was administered by an ophthalmologist in $56.7 \%$ of the cases, a career anaesthetist in $42.1 \%$ of the cases, a clinical assistant anaesthetist in $0.3 \%$ of the cases, and staff were not recorded in $0.9 \%$ of the cases.

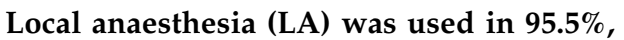
with topical anaesthesia alone in $22.3 \%$ (range by site, $0-99.8 \%)$, topical and intracameral in 4.7\% (range, $0-24.1 \%$ ), subtenons in $46.9 \%$ (range, $0-81.8 \%$ ), peribulbar in $19.5 \%$ (range, $0-63.4 \%$ ), and retrobulbar in $0.5 \%$ (range, $0-5.3 \%$ ). One or more minor complications occurred in $4.3 \%$ of 38058 local blocks administered by either sharp needle or subtenons (blunt) cannula. Minor complications were 2.3 times more common with subtenons blocks $(P<\mathbf{0 . 0 0 1})$. Serious complications, defined as sight or life threatening occurred in 25 eyes, $0.066 \%$, undergoing sharp needle or subtenons cannula blocks. Sharp needle techniques had a 2.5-fold increased risk of serious complications compared with subtenons cannula techniques $(P=0.026)$. Conclusion Subtenons anaesthesia was the most widely used anaesthetic technique for
N El-Hindy ${ }^{1}$, RL Johnston ${ }^{2}$, P Jaycock ${ }^{3}$, T Eke ${ }^{4}$, AJ Braga², DM Tole ${ }^{3}$, P Galloway', JM Sparrow ${ }^{3,5}$ and the UK EPR user group cataract surgery but wide variation existed by site. There was a low rate of reported LA complications. There was a statistically significant increased risk of serious complications with sharp needle anaesthesia compared with subtenons technique.

Eye (2009) 23, 50-55; doi:10.1038/sj.eye.6703031; published online 14 March 2008

Keywords: cataract surgery; local anaesthesia; complications; electronic patient records; Cataract National Dataset

\section{Introduction}

Cataract surgery is the most commonly performed operation in the National Health Service (NHS) and the number performed annually has increased from 105000 in $1990^{1}$ in the UK, to 287000 in England during 20052006. ${ }^{2}$ This marked improvement in throughput and efficiency has been made possible by the almost universal switch to day case phacoemulsification surgery under local anaesthesia (LA). The use of local anaesthetic techniques has risen from $46 \%$ in $1990^{1}$ to $86 \%$ in $1997^{3}$ and $96 \%$ in $2003 .{ }^{4}$ There have also been major changes in the local anaesthetic techniques used, with peribulbar and retrobulbar being used in 65.6 and $16.9 \%$ of cases, respectively, in the $1996^{5}$ survey, falling to $30.6-47.7$ and $0.8-3.5 \%$, respectively, in $2003,4,6$ subtenons anaesthesia increasing from 6.7 to $16.8-42.6 \%$ and topical anaesthesia increasing from 2.9 to $9.9-33.3 \%$ over the same time period. ${ }^{4-6}$ The use of sedation with local 
anaesthesia (LA) has fallen from $6 \%$ in $1996^{5}$ to $3.9 \%$ in 2003. ${ }^{4,6}$

Day case ophthalmic surgery under LA has been shown to be safe $\mathrm{e}^{7-9}$ and is associated with the least disruption to the patient's normal daily activity. ${ }^{9,10}$ The choice of anaesthesia depends on a number of factors, including patient psychology, the particular features of the globe and the orbit, the anticipated surgical difficulty and the experience of the operating surgeon. Ocular anaesthesia may be complicated by both ophthalmic and systemic factors. There have been reports of potentially life-threatening events, including brainstem anaesthesia, dysrhythmias and cardiovascular depression. ${ }^{8,11-15}$ The National Survey of Local Anaesthesia for Ocular surgery in 1996 estimated the incidence of potentially lifethreatening events to be 3.4 per $10000^{11}$ cases, though this was thought to be an underestimate of the true rate. In addition, there have been many documented cases of needle trauma to structures within the orbit during LA, some of which have caused significant loss of vision. ${ }^{411,16-27}$ Most of these adverse events have been reported with sharp needle techniques (retrobulbar and peribulbar anaesthesia); ${ }^{411,16-27}$ however, there have been no large randomised controlled trials to compare the safety of different local anaesthetic techniques.

Detailed record keeping is a prerequisite for clinical governance and audit, but few hospital ophthalmology departments have invested in the necessary information technology infrastructure to prospectively collect the Cataract National Dataset as a by-product of normal clinical care. Consequently few surgeons, anaesthetists, managers, purchasers of health care, or patients have a detailed knowledge of the outcomes associated with the use of LA. ${ }^{6}$ This situation falls short of expected professional standards outlined in the NHS plan,, ${ }^{28}$ a government initiative to improve the NHS.

The primary aim of this study was to examine anaesthetic techniques and complications of cataract surgery in a large sample of operations performed in the UK and to update benchmark standards of clinical care.

\section{Methods}

The methods employed in this study have been described in detail in the first paper in this series. ${ }^{29}$ Briefly, NHS Trusts using electronic patient record (EPR) systems for routine cataract surgery were invited to submit data for analysis. Following appropriate consents, data were extracted in an anonymised form such that all patient identifiers were stripped out, and hospitals and health-care professionals were pseudo-anonymised. Extracted data were assessed for conformity with the Cataract National Dataset ${ }^{30}$ in terms of format and completeness within the Royal College of
Ophthalmologists Dataset Working Group (chaired by JMS). Data from 12 Trusts using a single EPR system (Medisoft Ophthalmology, Medisoft Limited, Leeds, UK) were deemed of sufficient quality for analysis and these data form the basis of these series of reports.

Information on the professional group and grade of the person administering the anaesthetic, anaesthetic technique, anaesthetic and sedative drugs, and anaesthetic complications was available. Either the anaesthetist or operating surgeon could complete the anaesthetic data collection fields. To balance completeness, speed and accuracy of data entry, the Medisoft EPR allows some fields to be defaulted for individual surgeons or anaesthetists (eg grade, anaesthetic technique, usual drugs used), but a compulsory choice must be made each time the anaesthetic complication field is completed. In earlier versions of this software, the anaesthetic complications field was not available for topical/intracameral local anaesthetic techniques and it was not possible to record a complication of topical/intracameral anaesthesia. This therefore limits our ability to comment on complications of topical anaesthesia and we have therefore excluded topical and topical/intracameral anaesthesia from the analysis of complications. For the purpose of this report on LA for cataract surgery, complications were defined by the authors as serious if they were considered to be potentially life threatening (systemic) or sight threatening (ocular/orbital), and minor if worthy of recording but not in the serious category. Statistical analysis was performed in Microsoft Excel and Stata.

\section{Results}

Twelve NHS Hospitals and 406 surgeons submitted data for this study on 55567 cataract operations undertaken between January 2001 and July 2006. No anaesthetic data were available for one case. Completeness of data entry of the anaesthetic fields for the remaining operations was at or above $98.2 \%$, with the exception of the local anaesthetic complications field where it was $100 \%$ for cases performed under sharp needle (retrobulbar, peribulbar, subconjunctival, or combinations of these) and subtenons cannula anaesthesia, but was of unknown completeness for cases performed under topical and topical/intracameral anaesthesia (see Methods). Overall, $53043(95.5 \%)$ of operations were performed using local anaesthetic techniques and $4.5 \%$ under general anaesthesia. The percentage of operations and variation by site of each local anaesthetic technique are listed in Table 1 along with the professional group of the person administering the anaesthetic and their grade. Overall, anaesthesia was delivered by a consultant on $62.1 \%$ of 
Table 1 Anaesthetic technique and details of staff administering anaesthesia for 55566 operations (no anaesthetic data available for one case)

\begin{tabular}{|c|c|c|}
\hline & Number (\%) & $\begin{array}{l}\text { Range (\%) } \\
\text { by site }\end{array}$ \\
\hline \multicolumn{3}{|c|}{ Anaesthetic type and technique $(\mathrm{n}=55566)$} \\
\hline Local anaesthesia alone & $53043(95.5)$ & $75.1-100$ \\
\hline Topical & $12386(22.3)$ & 0-99.8 \\
\hline Topical and intracameral & $2599(4.7)$ & $0-24.1$ \\
\hline Subtenons & $26045(46.9)$ & $0-81.8$ \\
\hline Peribulbar & $10843(19.5)$ & $0-63.4$ \\
\hline Retrobulbar & $291(0.5)$ & $0-5.3$ \\
\hline Combinations including subconj & $879(1.6)$ & - \\
\hline General anaesthesia $^{a}$ & $2523(4.5)$ & $0-24.9$ \\
\hline \multicolumn{3}{|c|}{$\begin{array}{l}\text { Professional group administering anaesthetic including GA } \\
(\mathrm{n}=55566)\end{array}$} \\
\hline Surgeon & $31507(56.7)$ & $0-100$ \\
\hline Anaesthetist (including GA) & $23405(42.1)$ & $0-99.1$ \\
\hline Clinical assistant anaesthetist & $180(0.3)$ & $0-4.3$ \\
\hline Not recorded & $474(0.9)$ & $0-4.0$ \\
\hline \multicolumn{3}{|c|}{ Grade of doctor administering anaesthetic including $G A(\mathrm{n}=55566)$} \\
\hline Consultant & $34491(62.1)$ & $19.1-87.2$ \\
\hline Associate specialist & $6438(11.6)$ & $0-41.1$ \\
\hline Staff grade & $1405(2.5)$ & $0-12.9$ \\
\hline General practitioner anaesthetist & $276(0.5)$ & $0-21.1$ \\
\hline Fellow & $1488(2.7)$ & $0-12.9$ \\
\hline Specialist registrar & $9067(16.3)$ & $0-51.8$ \\
\hline Senior house officer & $1412(2.5)$ & $0-14.2$ \\
\hline Not recorded & $989(1.8)$ & $0-10.5$ \\
\hline
\end{tabular}

$\mathrm{GA}=$ general anaesthesia.

${ }^{a}$ General anaesthesia with or without supplemental local block. subconj, subconjunctival local anaesthetic infiltration.

occasions. Sedation, in addition to LA, was used in $1.4 \%$ of cataract operations.

Following exclusion of topical/intracameral technique, there were 38058 cases of LA for which robust data on complications were available. Among these, no complications were seen in $95.6 \%$ of cases. One or more minor anaesthetic complications were documented in 1635 eyes $(4.30 \%)$ and serious complications in 25 eyes $(0.066 \%)$ (Tables 2 and 3). Complication rates were similar for the various professional groups and grades of doctors delivering LA. The most commonly recorded minor complications were conjunctival chemosis $(2.03 \%)$ and subconjunctival haemorrhage (1.99\%). Serious systemic complications included atrial fibrillation (two cases), bradycardia (eight cases), intravascular injection (one case) with serious orbital/ocular complications, including peribulbar/retrobulbar haemorrhage (twelve cases) and suprachoroidal haemorrhage (two cases). One case of globe perforation was documented but the anaesthetic technique for this eye was recorded as being topical anaesthesia. There must, therefore, have been a data input error into the EPR, either in the anaesthetic technique field or in the complication field precluding
Table 2 Number and frequency of minor and serious complications of sharp needle and cannula (subtenons) local anaesthesia (excludes cases performed under topical or topical and intracameral anaesthesia, $n=38058$ )

\begin{tabular}{|c|c|}
\hline & Number (\%) \\
\hline \multicolumn{2}{|l|}{ Complications of local anaesthesia $\left(\mathrm{n}=38058\right.$ eyes $\left.^{\mathrm{a}}\right)$} \\
\hline No complications & $36398(95.6)$ \\
\hline 1 or more minor or serious complications ${ }^{a}$ & $1660(4.36)$ \\
\hline 1 or more minor complications ${ }^{\mathrm{a}}$ & $1635(4.30)$ \\
\hline Serious complications & $25(0.066)$ \\
\hline \multicolumn{2}{|c|}{ Minor complications $\left(\mathrm{n}=1792\right.$ complications arose in 1635 eyes $\left.^{\mathrm{a}}\right)$} \\
\hline Conjunctival chemosis & $774(2.03)$ \\
\hline Subconjunctival haemorrhage & $760(1.99)$ \\
\hline Eyelid haemorrhage/bruising & $85(0.22)$ \\
\hline Anxious & $52(0.14)$ \\
\hline Eye deviated from primary position & $48(0.13)$ \\
\hline Confused & $3(0.008)$ \\
\hline Nausea/vomiting & $1(0.003)$ \\
\hline Unspecified/other & $69(0.18)$ \\
\hline \multicolumn{2}{|c|}{ Serious complications $(\mathrm{n}=25$ complications arose in 25 eyes) } \\
\hline Peribulbar/retrobulbar haemorrhage & $12(0.032)$ \\
\hline Bradycardia & $8(0.021)$ \\
\hline Suprachoroidal haemorrhage & $2(0.005)$ \\
\hline Atrial fibrillation & $2(0.005)$ \\
\hline Intravascular injection & $1(0.003)$ \\
\hline
\end{tabular}

One case of globe perforation was recorded as having had topical anaesthetic prior to surgery and was excluded from analysis (see text).

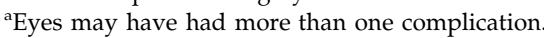

further analysis of this complication. Of the 'serious' complications, 13 occurred during 11134 cases undergoing peribulbar or retrobulbar anaesthesia and 12 during 26045 cases undergoing subtenons anaesthesia (Table 4).

Comparison between sharp needle vs subtenons cannula LA revealed a statistically significant 2.5 times $(P=0.026$; Fishers exact test $)$ increased risk of sustaining a 'serious' complication (ocular, orbital, or systemic) with sharp needle techniques. This included a significant 4.6fold $(P=0.009)$ increased risk of sustaining a peribulbar/ retrobulbar haemorrhage with sharp needle modalities compared with subtenons techniques. For minor complications, the opposite was observed, there was a significant 2.3-fold increased risk $\left(P<0.001 ; \chi^{2}\right.$ test) of a minor complication with subtenons compared with sharp needle techniques.

\section{Discussion}

This large audit surveyed anaesthesia for 55567 cataract operations performed between January 2001 and July 2006 (missing anaesthetic data for one operation). The vast majority of cases (95.5\%) were performed using LA without sedation, with subtenons LA being the most 
Table 3 Eyes associated with one or more minor or serious anaesthetic complications by professional group administering anaesthetic, by grade of doctor and by local anaesthetic technique for sharp needle and cannula (subtenons) local anaesthesia (excludes cases performed under topical or topical and intracameral anaesthesia, $n=38058$ )

\begin{tabular}{|c|c|c|}
\hline $\begin{array}{l}\text { Complications of local } \\
\text { anaesthesia }(\mathrm{n}=38058 \\
\left.\text { eyes }^{\mathrm{a}}\right)\end{array}$ & $\begin{array}{c}\text { No complications } \\
\text { number }(\%)\end{array}$ & $\begin{array}{c}\text { Any complications } \\
\text { number }(\%)\end{array}$ \\
\hline \multicolumn{3}{|c|}{ Complications by professional group administering anaesthetic } \\
\hline Surgeon & $19981(94.7)$ & $1660(4.36)$ \\
\hline Anaesthetist & $16022(96.8)$ & $1127(5.34)$ \\
\hline $\begin{array}{l}\text { Clinical assistant } \\
\text { anaesthetist }\end{array}$ & $106(99.1)$ & $523(3.16)$ \\
\hline Not recorded & $289(97.0)$ & $1(0.93)$ \\
\hline \multicolumn{3}{|c|}{ Complications by grade of doctor administering anaesthetic } \\
\hline Consultant & $23714(95.7)^{\circ}$ & $1074(4.33)$ \\
\hline Associate specialist & $1828(97.6)$ & $45(2.40)$ \\
\hline Staff grade & $251(95.4)$ & $12(4.56)$ \\
\hline $\begin{array}{l}\text { General practitioner } \\
\text { anaesthetist }\end{array}$ & $255(94.1)$ & $16(5.90)$ \\
\hline Fellow & $1199(96.1)$ & 49 (3.93) \\
\hline Specialist registrar & $7211(95.1)$ & $369(4.87)$ \\
\hline Senior house officer & $1286(95.1)$ & $66(4.88)$ \\
\hline Not recorded & $654(95.8)$ & $29(4.25)$ \\
\hline \multicolumn{3}{|c|}{ Complications by local anaesthetic type } \\
\hline Subtenons ${ }^{\mathrm{b}}$ & $24660(94.7)$ & $1385(5.32)$ \\
\hline Peribulbar & $10646(98.2)$ & $197(1.82)$ \\
\hline Retrobulbar & $288(99.0)$ & $3(1.03)$ \\
\hline Combinations & 804 (91.5) & $75(8.53)$ \\
\hline $\begin{array}{l}\text { Any sharp needle } \\
\text { technique }^{\mathrm{a}}\end{array}$ & $11738(97.7)$ & $275(2.29)$ \\
\hline \multicolumn{3}{|l|}{ Total } \\
\hline $\begin{array}{l}\text { Eyes may have had } \\
\text { more than one } \\
\text { complication }\end{array}$ & 36398 (95.6) & $1660(4.36)$ \\
\hline
\end{tabular}

${ }^{\mathrm{a}}$ Any sharp needle technique $=$ peribulbar + retrobulbar + combinations. 'Statistically significant differences in rates of 'any complications' were found between the subtenons and peribulbar groups and also between subtenons and 'any sharp needle technique' ( $\chi^{2}$ tests, $P<0.001$ for both comparisons).

commonly used technique (46.9\%). There was, however, wide variation of anaesthetic technique by NHS site with several centres almost exclusively favouring one anaesthetic technique or another (Table 1). There was a low rate of reported complications with all LA techniques, but evidence of a significantly higher rate of serious (life or sight threatening) complications for sharp needle (peribulbar and retrobulbar) compared with subtenons cannula techniques. Conversely, minor complications (mainly conjunctival chemosis and subconjunctival haemorrhage) were more common with subtenons cannula techniques.
The study may not be fully representative of UK practice as a whole, because only departments that were using the Medisoft EPR system were able to provide data of appropriate format and completeness within the tight time frame of the study. It is possible that these units may take a particular interest in their cataract care pathway and techniques. A 2003 postal survey of all UK consultants indicated that $96 \%$ of cataract surgery was carried out using LA, comprising 34\% sharp needle, $43 \%$ subtenons, and $21 \%$ topical/intracameral. ${ }^{4}$ The present study similarly found that almost $96 \%$ of cataract surgery was performed under LA, but with lower rates of sharp needle (19.5\%) and higher rates of subtenons (46.9\%) and topical/intracameral (27\%) techniques. The authors consider that the most likely explanation for the difference between this study and the 2003 survey is a continued trend away from sharp needle techniques, as $86 \%$ of data in this study were collected between January 2004 and July 2006.

Data on complications were complete (100\%) for 38058 sharp needle and subtenons cannula techniques, with low complication rates reported for each. The overall rate of $4.36 \%$ for 'any minor or serious' problem was similar to that recorded in the 1996 prospective survey of LA complications. ${ }^{11}$ However, the present study found fewer reports of 'serious' complications (sight threatening or life threatening) than we would have expected from the literature. Although recording of complications was $100 \%$ for sharp needle or subtenons cannula anaesthesia, it is still possible that some serious complications were missed. There are several possible ways in which an underreporting bias may have arisen. At some centres, the anaesthetist completes the anaesthetic fields on the EPR immediately after the anaesthetic, but at other sites these details are entered by the surgeon only after surgery has been completed. In the latter situation, there is the potential for complications not to be communicated to the surgeon or to be forgotten by the surgeon at the time of data entry. Alternatively, where the anaesthetist completes the record prior to surgery a complication may only come to light during or after surgery and may thus be missed off the record. Some clinicians may consider certain minor complications of LA as trivial and these may therefore not be recorded. Some serious complications (eg globe perforation) may not be noticed until some time after the surgery, by which time the EPR will already have been completed. If a 'life-threatening' complication such as brainstem anaesthesia has occurred, an EPR might not be completed if the team is busy transferring the patient to intensive care, or if the operation was not commenced. Underreporting bias is a feature of all large studies of LA safety but data capture for anaesthetic complications of sharp needle and cannula anaesthetic techniques was $100 \%$, which at least 
Table 4 Serious local anaesthetic complications by sharp needle (peribulbar or retrobulbar) and cannula (subtenons) local anaesthetic techniques

\begin{tabular}{|c|c|c|c|}
\hline Serious complications & $\begin{array}{l}\text { Subtenons } \\
(\mathrm{n}=26045)\end{array}$ & $\begin{array}{c}\text { Peribulbar or } \\
\text { retrobulbar } \\
(\mathrm{n}=11134)\end{array}$ & P-value \\
\hline $\begin{array}{l}\text { Peribulbar/retrobulbar } \\
\text { haemorrhage }^{\text {a }}\end{array}$ & 4 & 8 & 0.009 \\
\hline Bradycardia & 4 & 4 & 0.251 \\
\hline Atrial fibrillation & 2 & 0 & 1.000 \\
\hline Intravascular injection & 1 & 0 & 1.000 \\
\hline $\begin{array}{l}\text { Suprachoroidal } \\
\text { haemorrhage }\end{array}$ & 1 & 1 & 0.509 \\
\hline $\begin{array}{l}\text { Total (all serious } \\
\text { complications) }\end{array}$ & 12 & 13 & 0.026 \\
\hline
\end{tabular}

${ }^{\mathrm{a} A}$ statistically significant difference $(P<0.05$, Fishers exact test $)$ was found between the subtenons and the peribulbar/retrobulbar group for 'peribulbar/retrobulbar haemorrhage' and for 'all complications' (bold text).

confirms that the users of the EPR had made an active decision every time this compulsory field was completed.

Minor complications were uncommon overall (4.30\%), with conjunctival chemosis $(2.03 \%)$ and subconjunctival haemorrhage $(1.99 \%)$ being the most frequently recorded (Table 2). A degree of subconjunctival haemorrhage is likely with all sharp needle or subtenons cannula anaesthetic techniques and hence a higher rate of these minor complications might be expected. It is likely that users of the EPR only choose to record the presence of minor anaesthetic complications when they are more prominent than might normally be expected for that technique. Minor complications arose significantly more frequently with subtenons cannula techniques (5.32\%) when compared to peribulbar $(1.82 \%)$ or 'any sharp needle technique' (2.29\%; Table 3$)$. This observation is unsurprising since the larger incision and unavoidable conjunctival trauma involved in subtenons cannula placement make superficial (subconjunctival) haemorrhage more likely in comparison with sharp needle entry.

Serious complications were noted in 25 cases $(0.066 \%$; Table 4). This confirms the previously widely held view that serious adverse effects of sharp and cannula LA are very rare. In this series, one serious complication (globe perforation) was documented under topical anaesthesia but this must be an input error into the EPR with either the anaesthetic technique or complication being entered incorrectly, making further analysis of this complication impossible. Serious complications occurred in 12 of 26045 cases of subtenons anaesthesia, and in 13 of 11134 cases of peribulbar/retrobulbar anaesthesia, representing a 2.5 times higher risk $(P=0.026)$ of a serious complication with sharp needle blocks. Peribulbar/ retrobulbar haemorrhages were the main contributors to this effect, arising 4.6 times more frequently $(P=0.009)$ with sharp needle techniques. As with other papers in this series, caution should be observed where statistical significance is borderline since an unknown number of subjects will have contributed two eyes to the analysis.

A prospective randomised controlled trial to directly address a comparison of the safety profile of the various local anaesthetic techniques has never been carried out. The number of patients required to reach statistical significance would be so large that it is unlikely that such a trial would ever be performed. A large observational study such as this is however able to provide some insights into this question using outcome-based research methodology ${ }^{31}$ and these results accord with what might intuitively be expected. This study therefore adds further weight to the view that sharp needle anaesthetic techniques should be reconsidered for routine cataract surgery due to an increased risk of rare but serious complications.

This study demonstrates the ability of a specialtyspecific EPR system to collect the Cataract National Dataset as a by-product of normal clinical care and to continuously, prospectively and rapidly audit service trends and rare complications of LA for cataract surgery. With modest information technology investment, NHS eye departments could deliver detailed audit and clinical governance as outlined in the NHS Plan. ${ }^{28}$

\section{Acknowledgements}

Material from this paper was presented as an oral presentation at the European Society of Cataract and Refractive Surgeons 2006, and as a poster at the Royal College of Ophthalmologists Annual Congress 2007.

Robert Johnston is a Director of Medisoft Limited. Peter Galloway is an advisor to Medisoft in relation to glaucoma but not cataract.

\section{References}

1 Courtney P. The National Cataract Surgery Survey: I. method and descriptive features. Eye 1992; 6: 487-492.

2 Department of Health Hospital Episode Statistics. http://www.hesonline.nhs.uk/Ease/servlet/ ContentServer? siteID = 1937\&categoryID =193. (site accessed on 4 January 2007).

3 Desai P, Reidy A, Minassian DC. Profile of patients presenting for cataract surgery: national data collection. Br J Ophthalmol 1999; 83: 893-896.

4 Eke T, Thompson JR. Serious complications of local anaesthesia for cataract surgery: a one-year national survey in the United Kingdom. Br J Ophthalmol 2007; 91: 470-475.

5 Eke T, Thompson JR. The National Survey of Local Anaesthesia for Ocular Surgery. I. Survey methodology and current practice. Eye 1999; 13: 189-195. 
6 Johnston RL, Sparrow JM, Canning CR, Tole D, Price NC. Pilot National Electronic Cataract Surgery Survey I. Eye 2005; 19: 788-794.

7 Forest FC. Local anaesthesia or general anaesthesia? In: Johnson RW, Forest FC (eds). Local and General Anaesthesia for Ophthalmic Surgery. Butterworth Heinemann: Oxford, 1994.

8 Hamilton RC, Gimbel HV, Strunin L. Regional anaesthesia for 12000 cataract extractions and intraocular implantation procedures. Can J Anaesth 1998; 35: 615-623.

9 Campbell DNC, Lim M, Kerr Muir M, O'Sullivan G, Falcon $\mathrm{M}$, Fison $\mathrm{P}$ et al. A prospective randomized study of local $v$ s general anaesthesia for cataract surgery. Anaesthesia 1993; 48 : 422-428.

10 Cooper JM. Development of day-case cataract surgery. A literature review. Br J Nurs 1996; 5: 1327-1333.

11 Eke T, Thompson JR. The National Survey of local anaesthesia for ocular surgery. II. Safety profiles of local anaesthesia techniques. Eye 1999; 13: 196-204.

12 Nicoll JMV, Acharya PA, Ahlen K, Baguneid S, Edge KR. Central nervous system complications after 6000 retrobulbar blocks. Anaesth Analg 1987; 66: 1298-1302.

13 Davies II DB, Mandel MR. Efficiency and complication rate of 16224 consecutive peribulbar blocks: a prospective multicenter study. J Cataract Refract Surg 1994; 20: 327-337. Erratum published in J Catarct Refract Surg 1994; 20: 673.

14 Meyer EF, Ramirez RC, Boniuk I. Grand mal seizures after retrobulbar block. Arch Ophthalmol 1978; 96: 847.

15 Wittpenn JR, Rapoza P, Sternbern Jr P, Kuwashima L, Saklad J, Patz A. Respiratory arrest following retrobulbar anaesthesia. Ophthalmology 1986; 93: 867-870.

16 Duker JS, Belmont JB, Benson WE, Brooks HL, Brown GC, Feedrman JL et al. Inadvertent globe perforation during retrobulbar and peribulbar anaesthesia. Ophthalmology 1991; 98: 519-526.

17 Hay A, Flynn Jr HW, Hoffman JI, Rivera AH. Needle penetration of the globe during retrobulbar and peribulbar injections. Ophthalmology 1991; 98: 1017-1024.

18 Gillow JT, Aggarwal RK, Kirby GR. A survey of ocular perforation of the globe during ophthalmic local anaesthesia in the United Kingdom. Eye 1996; 10: 537-538.
19 Paulter SE, Grizzard WS, Thompson LN, Wing GL. Blindness from retrobulbar injection into the optic nerve. Ophthalmic Surg 1986; 17: 334-337.

20 Hersch M, Baer G, Dieckert JP, Lambert HM, Shore JW. Optic nerve enlargement and central retinal artery occlusion secondary to retrobulbar anaesthesia. Ann Ophthalmol 1989; 21: 195-197.

21 Kraushar MF, Seelendfreund MH, Freilich DB. Central retinal artery closure during orbital hemorrhage from retrobulbar injection. Trans Am Acad Ophthalmol Otolaryngol 1974; 78: OP65-OP70.

22 Morgan CM, Scahtz H, Vine AK, Cantrill HL, Davidorf FH, Gitter KA et al. Ocular complications associated with retrobulbar injections. Ophthalmology 1988; 95: 660-665.

23 Puustjarvi T, Purhonen S. Permanent blindness following retrobulbar hemorrhage after peribulbar anaesthesia for cataract surgery. Ophthalmic Surg 1992; 23: 450-452.

24 Hamed LM. Strabismus presenting after cataract surgery. Ophthalmology 1991; 98: 247-252.

25 Hamilton SM, Elsas FJ, Dawson TL. A cluster of patients with inferior rectus restriction following local anaesthesia for cataract surgery. J Pediatr Ophthalmol Strabismus 1993; 93: 573-577.

26 Rao VA, Kawatra VK. Ocular myotoxic effects of local anaesthetics. Can J Ophthalmol 1988; 23: 171-173.

27 Klein ML, Jampol LM, Condon PI, Rice TA, Sergeant GR. Central retinal artery occlusion without retrobulbar hemorrhage after retrobulbar anaesthesia. Am J Ophthalmol 1982; 93: 573-577.

28 The NHS Plan. http://wwwdh.gov.uk/en/ Policyandguidance/Organisationpolicy/Modernisation/ DH 4082690.

29 Jaycock P, Johnston RL, Taylor H, Adams M, Tole DM Galloway $\mathrm{P}$ et al. The Cataract National Dataset electronic multi-centre audit of 55567 operations: updating benchmark standards of care in the United Kingdom and internationally. Eye advance online publication 23 November 2007; doi:10.1038/sj.eye.6703015.

30 The Cataract National Dataset. Do once and share. www.rcophth.ac.uk/about/college/doas-cataract.

31 Javitt JC. Rule Britannia. Eye 2005; 19: 728-729. 